\title{
Diabetic Renal-Retinal Syndrome and Inflammatory Markers of Acute Phase
}

\author{
Francisco Jesús Sepúlveda-Cañamar ${ }^{1 *}$, Raúl Treviño Hernández ${ }^{1}$, \\ Joaquín Darío Treviño Baéz ${ }^{2}$, Jesús H. González Cortés ${ }^{3}$ \\ ${ }^{1}$ Ophtalmology and Nephrology Services, Unidad Médica de Atención Ambulatoria, Instituto Mexicano del \\ Seguro Social, San Pedro Garza García, México \\ ${ }^{2}$ Universidad Juárez del Estado de Durango, Durango, México \\ ${ }^{3}$ Ophtalomology Department of Universidad Autónoma de Nuevo León, San Nicolás de los Garza, Mexico \\ Email: ${ }^{\text {fco }}$ sepulveda67@hotmail.com
}

Received 16 May 2014; revised 10 June 2014; accepted 8 July 2014

Copyright (C) 2014 by authors and Scientific Research Publishing Inc.

This work is licensed under the Creative Commons Attribution International License (CC BY). http://creativecommons.org/licenses/by/4.0/

(c) (i) Open Access

\begin{abstract}
Objective: To determine the association between the acute inflammatory markers and Diabetic Renal-Retinal Syndrome in our patients. Methods: A total of 44 patients were included in this transverse (cross sectional), observational, analytical, and comparative study. Two groups of patients were created. Results: In patients with chronic renal failure, stages 3, 4, or 5 (scale 1 to 5) were identified and divided into two groups: Group I (Patients with concomitant diabetic retinopathy stabilized with photocoagulation) 22 patients. Group II (Patients with progression of retinopathy, after photocoagulation, in the form of intraocular bleeding) 22 patients. The number of patients with chronic renal failure in stage 3 was: Group I; 16. In Group II; 12 patients (OR: 1.0). Stage 4: Group I; 4 patients. Group II: 3 patients (OR: 1.0, CI 95\%; 0.3843 - 2.021). Stage 5: Group I; 2 patients. Group II; 7 patients (OR: 1.8148, CI 95\%; 1.0448 - 3.1523; Chi-squared $\left(x^{2}\right)$ 2.7450, $p=$ 0.097). $t$-Test found statistical significance in Erythrocyte Sedimentation Rate (ESR): $p<0.0001$ (CI 95\%; 7.8959 - 23.2515); $R=0.56 \mathrm{p}=0.001$; and $\mathrm{OR}=1.959$ (CI 95\%; $1.193-3.217$ ). By non-parametric tests, C-reactive protein with binomial test showed $p<0.001$. ESR showed $p<0.001$ with $U$ of Mann Whitney. Conclusions: With this study revealed a possible association of inflammatory markers with Diabetic Renal-Retinal Syndrome.
\end{abstract}

\section{Keywords}

Diabetic Renal-Retinal Syndrome, Erythrocyte Sedimentation Rate, C-Reactive Protein

\footnotetext{
${ }^{*}$ Corresponding author.
}

How to cite this paper: Sepúlveda-Cañamar, F.J., Hernández, R.T., Baéz, J.D.T. and Cortés, J.H.G. (2014) Diabetic Renal-Retinal Syndrome and Inflammatory Markers of Acute Phase. Journal of Diabetes Mellitus, 4, 194-201. 


\section{Background}

Diabetic retinopathy is the third cause of blindness in developing countries and a leading cause of blindness in the people of the working-age. Hyperglycemia and high blood pressure are related with proliferative diabetic retinopathy. Once diabetic retinopathy or macular edema appears, threaten vision. Laser photocoagulation is a fundamental treatment to prevent vision loss [1].

Diabetic nephropathy is strongly associated with diabetic retinopathy, which is confirmed with proteinuria. Although up to $20 \%$ - $45 \%$ of type 2 diabetics with proteinuria have no concomitant diabetic retinopathy, with the presence of diabetic retinopathy, it is suggested a careful examination in order to detect diabetic nephropathy [2].

We recall that diabetic nephropathy is the leading cause of final stage in chronic kidney disease in United States as well as Europe. It is the responsible for up to $42 \%$ of new cases of chronic kidney disease. Proteinuria is the albumin excretion $>300 \mathrm{mg} / 24 \mathrm{~h}$ in at least 3 timed urine collections in absence of urinary infection or hematuria, coronary artery disease, level of serum creatinine $<150 \mu \mathrm{mol} / \mathrm{l}$ and absence of clinical features or laboratory data of another nephropathy or urinary tract disease [3].

Even glycosylated hemoglobin $\left(\mathrm{HbA}_{1 \mathrm{C}}\right)$ is an accepted standard on Glycemic Control in diabetic patients, microvascular complications can occur in patients with $\mathrm{HbA}_{1 \mathrm{C}}<7 \%$ [4]. Also, it is showed that high blood pressure has a causal relationship with kidney disease and it is a risk factor for the progression of diabetic retinopathy [5]. In fact, research has been conducted on the relationship of microvascular complications in diabetic patients by using excretion of urinary albumin together with C-reactive protein of high-sensitivity and creatinine among others variables [6].

In addition, earlier studies have reported the contribution of anemia to the pathogenesis and progression of both diabetic nephropathy and diabetic retinopathy in patients with diabetes mellitus [7]. Anemia has long been recognized as a marker of diabetic kidney disease [8], recently it has been found a relationship with diabetic retinopathy. Conway, has mentioned that anemia causes a stimulation of the production of erythropoietin caused by general hypoxia which contributes to microvascular disease in both kidneys and retinas of diabetic patients [9].

Nevertheless, the role of inflammation in diabetes mellitus is an issue rarely discussed. Although, it is accepted that hyperglycemia is a leading cause of microvascular complications, as mentioned earlier, it has been studied the association between inflammatory markers, locals and systemic, such as cell adhesion molecules (vascular adhesion cell molecules-1, VACM-1; intracellular adhesion molecules-1, ICAM 1) pro-inflammatory cytokines (interleukin-6, tumor necrosis factor-alpha and C-reactive protein) with the development and progression of diabetic microvascular complications, previously mentioned [10] [11]. Even, it was found an association between homocystein and diabetes mellitus in people with or with no chronic renal disease and with diabetic macular edema, which is an advanced stage of retinopathy. This data suggests the relationship between diabetic retinopathy and kidney disease in diabetics.

By reviewing the literature, in 1980, Friedman reported for the first time the "Diabetic Renal-Retinal Syndrome” [12]. The study mentions that more than 90\% of uremic type 1 diabetics will have some degree of retinopathy and 50\% will become blind or impaired sight. In 1987, Cowan reported that nephropathy is present in $35 \%$ - 50\% of the diabetics with symptomatic retinopathy [13]. In 1999, Sessa and collaborators found that classic Kimmelstiel-Wilson (KW) glomerulopathy is associated with Proliferative Diabetic Retinopathy (Diabetic Renal-Retinal Syndrome) [14]. In latest report in 2001 about this syndrome, it is confirmed that 136 diabetic patients who underwent renal biopsy with moderate or severe glomerulosclerosis could have retinopathy in more significant form than those with mild kidney disease [15].

Inflammatory markers of diabetes were studied alone in different systems, not together, from cell adhesion molecules, pro-inflammatory citokines and CRP [10] [11] to chemokines regulated on activation, expressed and presumably secreted normal T-cell (RANTES) and stromal cell-derived factor (SDF) [16], the previously mentioned for diabetic retinopathy and only CRP for diabetic nephropathy [17].

Nevertheless, except for CPR, the rest of the variables are too specific for common laboratory. Although the inflammatory process can explain why many patients who have a good metabolic control exhibit deterioration of their conditions of both the retina and kidney could be included within the diabetic retinal-renal syndrome.

In our personal experience, we found that more than $90 \%$ of patients who underwent vitrectomy caused by intraocular bleeding showed kidney failure as well. Large portion of patients were unaware of having kidney 
disease, however pre-operative lab tests showed altered laboratory data from both serum creatinine, urea nitrogen and urea. Most of those patients had been treated previously with laser photocoagulation of solid state (Zeiss Visulas 532s Photocoagulation Laser) in our medical unit caused by concomitant diabetic retinopathy. Nevertheless, they showed progression of the disease. This leads to our following research question:

Is there association between the inflammatory markers of acute phase C-reactive protein and erythrocyte sedimentation rate with diabetic chronic renal disease and the progression of diabetic retinopathy after photocoagulation (Diabetic Renal-Retinal Syndrome) in our population?

\section{Materials and Methods}

This transverse (cross sectional), observational, analytical, and comparative study was conducted from March 2011 to September 2013. The sample was calculated by EPI-INFO ${ }^{\odot}$ to obtain 20 patients in each group for a non-matched comparative study. By using a software, we requested the size sample for a cross sectional, non matching study; where the expected frequency of having the pathology in the stabilized patients was of $45 \%$; with an $80 \%$ of power $(1-\beta)$ and a CI of $95 \%$.

- Formula for a comparative study between two proportions:

$\mathrm{N}=\left(\mathrm{p}_{1}\right)\left(\mathrm{q}_{1}\right)+\left(\mathrm{p}_{2}\right)\left(\mathrm{q}_{2}\right)(\mathrm{k}) /\left(\mathrm{p}_{1}-\mathrm{p}_{2}\right)^{2}$, with a $90 \%$ of power:

$\mathrm{K}=(\mathrm{Z} \alpha+\mathrm{Z} \beta)^{2}=8.6$

If the $45 \%$ of the stabilized group will present intraocular bleeding: $\mathrm{p}_{1}=45$

If the $90 \%$ of the non stabilized group will have intraocular bleeding: $\mathrm{p}_{2}=90$

$\mathrm{n}=(45)(65)+(90)(10)(8.6) /(45-90)^{2} ; \mathrm{n}=3825(8.6) / 2025 ; \mathrm{n}=32895 / 2025$;

$\mathrm{n}=16.2 ; \mathrm{n}=16$ patients per group.

- Velasco-Rodríguez VM, Martínez Ordaz VA, Roiz Hernández J, Huazano García F, Nieves Rentería A. Muestreo y Tamaño de Muestra. Una guía práctica para personal de salud que realiza investigación. E-libro. net. ISBN 987-9499-36-0. PP 51-54.

The patients from ophthalmology service were included according to the following criteria: 1) with diabetes mellitus; 2) with diabetic nephropathy, were aware or unaware of having it; 3) with diabetic retinopathy was treated with photocoagulation; 4) with fluorescein angiography (previously taken with Zeiss FF 450 plus Fundus Camera). Diabetic retinopathy diagnosis was determined according to pre-established criteria [18].

Patients with diabetic kidney disease were automatically included. Patients which were unaware of having kidney disease were detected if they have a glomerular filtration rate from 0 and $89 \mathrm{ml} / \mathrm{min}$, based on CKD-EPI creatinine equation [19] were included. This is, it took into account chronic renal disease from mild (stage 2), moderate (stage 3), severe (stage 4), and established renal failure (stage 5). The following parameters were obtained in all patients: 1) Sex; 2) Age; 3) Duration of diabetes mellitus; 4) Prior knowledge of HTA; 5) Hemoglobin; 6) Glucose; 7) Cholesterol; 8) Triglycerides; 9) Urea; 10) Urea nitrogen; 11) Creatinine; 12) Glycosylated hemoglobin; 13) Systolic blood pressure; 14) Diastolic blood pressure; 15) Erythrocyte Sedimentation Rate; 16) C-reactive protein.

The interest in the last two parameters is answered on the objective of this study, to investigate the most common inflammatory factors of acute phase and based on the previous studies that mention biological markers of inflammation and their relationship with diabetic nephropathy and retinopathy [6] [11] [17]. Others variables were requested based on prior studies of risk factors in Hispanics [20].

Two groups of patients were created:

1) Group I or stabilized patients (with no progression of diabetic retinopathy after photocoagulation, and diabetic chronic kidney disease).

2) Group II or patients with progression of diabetic retinopathy after photocoagulation and diabetic chronic kidney disease, which led to surgery caused by intraocular bleeding.

Thanks to our first study, we found that anemia was the main parameter that made the difference between patients with diabetic retinopathy who remained stables after photocoagulation versus patients with progression of the pathology, even after the photocoagulation. In this previous study, we did not much importance to the diabetic chronic kidney disease. But, when we check our reports, we realized that anemia was related to intraocular bleeding; we found that around $90 \%$ of the patients with intraocular bleeding finished in intraocular surgery, underwent in our medical unit, have diabetic chronic kidney disease. We wanted to compare both groups of the 
patients with diabetic chronic kidney disease in order to find a parameter, or parameters, that would explain that difference.

Patients were subdivided within each group according to the kidney failure stage by using CKD-EPI creatinine equation, aforementioned.

Patients who did not fulfill any requirement or with any other retinal pathology were excluded (for instance, age-related macular degeneration) and the patients who do not desire to continue in the trial or do not attend with lab test variables ordered were eliminated from the study.

All patients read and signed an informed consent form prior to their participation in the study according to the Helsinki Declaration and Mexican Laws on public health.

Statistical analysis were performed by using SPSS $20^{\mathrm{TM}}$ and Epidata software for searching descriptive statistical (percentages and frequencies) and analytical, both parametric and non-parametric.

We searched for percentages and frequencies, for the descriptive statistics, such as percentage of males versus females and the mean or average of the time with Diabetes mellitus. We used " $t$-Test" or "Student's test" to obtain the differences between the groups with the ordinal quantitative variables or parameters (Parametric), and the non parametric statistical analysis for the nominal and qualitative variables or parameters. Finally, we made a linear regression analysis with the most significant ordinal quantitative variables or parameters in order to confirm the results with the " $t$-Test". With the non parametric variables or parameters, the SPSS 20 automatically showed which analysis should undergo the variable or parameter. We did not choose the type of non parametric study with any of the variables.

\section{Results}

It was offered the participation of 225 patients, but only 105 patients fulfilled the main requirements, this is, to want to be involved in the study and to attend with lab tests ordered. From those patients it was selected 44 patients for the study:

Each group consisted of 22 patients: Group I or group with stabilized diabetic retinopathy after photocoagulation, Group II or group with progression of diabetic retinopathy after photocoagulation (with intraocular bleeding).

The remaining 61 patients who had completed lab tests had no chronic kidney disease.

Of the 44 patients: 9 were women (3 from group I or stabilized, 6 from group II or with progression) the remaining 35 patients were men (19 from stabilized group, 16 from group with progression).

Between women and men it was obtained an OR= 1.458 (95\% CI 0.811 - 2.621), with non-parametric binary test it was obtained a $\mathrm{p}<0.001$. Regarding the classification of diabetic retinopathy, it was obtained the following:

In Stabilized group (Group I): 19 patients with pre-proliferative diabetic retinopathy and 3 patients with proliferative diabetic retinopathy.

In Group with progression (Group II): 22 patients with proliferative diabetic retinopathy. No patients with pre-proliferative diabetic retinopathy were found.

From this, it was obtained Pearson chi-squared 33.440, with Fisher exact test of $\mathrm{p}<0.001$ and OR $=8.3$ (95\%; 2.883 - 24.090).

Patients were aware of having kidney disease: 15 (34.1\%).

Patients were unaware of having kidney disease: 29 (65.9\%).

Concerning the stage of Chronic Kidney Disease, it was found patients with stages 3, 4, or 5. We did not find patients with stage 2 of chronic kidney disease. The number that fulfilled each stage was as follows:

Stage 3: 16 patients in group I or stabilized group; 12 patients in group II or group with progression of diabetic retinopathy $(\mathrm{OR}=1.0)$.

Stage 4: 4 patients in group I; 3 patients in group II (OR = 1.0. 95\% CI; 0.3843 - 2.021).

Stage 5: 2 patients in group I; 7 patients in group II (OR $=1.8148 .95 \%$ CI $1.0448-3.1523$. Chi-squared 2.7450, $\mathrm{p}=0.097)($ Table 1$)$.

From the remaining variables it was obtained significant results by using $t$-Test with:

1) Cholesterol: $\mathrm{p}=0.038$ (95\% CI; 2.14119 - 71.20081).

2) Erythrocyte Sedimentation Rate: $\mathrm{p}<0.001$ (95\% CI; 7.89583-23.25154) (Table 2).

By applying LOGISTIC REGRESSION, only ESR obtained a significant result: $\mathrm{R}=0.56, \mathrm{p}<0.001$. 
Table 1. Comparison table between the stages of kidney chronic disease and diabetic retinopathy stages (stabilized group and the group with progression presentingintraocular bleeding).

\begin{tabular}{cccc}
\hline $\begin{array}{c}\text { Chronic kidney } \\
\text { disease stages }\end{array}$ & $\begin{array}{c}\text { Diabetic retinopathy } \\
\text { stable }\end{array}$ & $\begin{array}{c}\text { Proliferative diabetic retinopathy } \\
\text { (intraocular bleeding) }\end{array}$ & OR \\
\hline 2 & 0 & 0 & OR $=1.0$ \\
3 & 16 & 12 & OR: $1.0(95 \%$ CI; $0.3843-2.021)$ \\
4 & 4 & 3 & OR: $1.8148(95 \%$ CI $1.0448-3.1523 ;$ \\
Chi-squared 2.7450$) \mathrm{p}=0.097$
\end{tabular}

This table was made to show that effectively, with the exception of the final stage of chronic kidney disease, or stage 5 ; both stages 3 and 4 have almost the half of the patients with intraocular bleeding. This supports what was previously reported, that almost $50 \%$ of the patients with diabetic chronic kidney disease will present ocular complications, and how we obtained the sample size. It also supports what we were reported that patients in stage 5, at least in our population, do present intraocular complications, even if they were previously photocoagulated. The statistics was obtained by EPI DATA program. We used a $2 \times \mathrm{N}$ contingency table for a cross sectional study.

Table 2. $t$-Test. To compare averages of both populations in order to confirm that they are similar.

\begin{tabular}{|c|c|c|c|c|c|c|c|}
\hline \multirow[t]{2}{*}{ VARIABLE } & \multicolumn{2}{|c|}{ MEAN (Average) } & \multicolumn{2}{|c|}{$\begin{array}{l}\text { STANDARD } \\
\text { DEVIATION }\end{array}$} & \multirow[t]{2}{*}{ SIGNIFICANCE } & \multicolumn{2}{|c|}{$95 \%$ CI } \\
\hline & Stables & Proliferation & Stables & Proliferation & & Lower & Upper \\
\hline Age & 60.3 & 59.6 & $\begin{array}{c}10.7 \\
7.2\end{array}$ & & $p=0.793$ & -6.29469 & 4.84014 \\
\hline $\begin{array}{l}\text { Duration of DM } \\
\text { (years) }\end{array}$ & 16.9 & 18.7 & $\begin{array}{c}9 \\
5.3\end{array}$ & & $\mathrm{p}=0.430$ & -0.29631 & 9.56904 \\
\hline Hemoglobin g/dl & 12.3 & 11.7 & $\begin{array}{l}1.5 \\
1.9\end{array}$ & & $\mathrm{p}=0.299$ & -33.81060 & 14.21969 \\
\hline Glucose mg/dl & 133.7 & 113.6 & 68.6 & 38.9 & $\mathrm{p}=0.240$ & -54.01783 & 13.92694 \\
\hline Cholesterol mg/dl & 188 & 224.7 & 49.6 & 62.0 & $p=0.038$ & 2.14119 & 71.20081 \\
\hline Triglycerides mg/dl & 172.9 & 299.4 & $\begin{array}{c}89.9 \\
280.0\end{array}$ & & $\mathrm{p}=0.051$ & -0.70412 & 253.68594 \\
\hline Urea mg/dl & 67.4 & 114.5 & $\begin{array}{c}30.4 \\
197.0\end{array}$ & & $\mathrm{p}=0.310$ & -45.62517 & 139.72991 \\
\hline Urea Nitrogen mg/dl & 33.8 & 36.9 & 14.4 & 20.2 & $\mathrm{p}=0.565$ & -7.75845 & 14.01775 \\
\hline Creatinine mg/dl & 2.1 & 4.9 & 0.91 & 6.9 & $\mathrm{p}=0.062$ & -0.15026 & 5.91662 \\
\hline HbA1c \% & 7.9 & 7.7 & 1.8 & 1.6 & $\mathrm{p}=0.686$ & -1.30440 & $0-86622$ \\
\hline ESR & 33.9 & 49.4 & 11.9 & 11.7 & $\mathrm{p}<0.001$ & 7.89583 & 23.25154 \\
\hline Systolic BP mm Hg & 137.6 & 138.6 & 21.6 & 23.1 & $\mathrm{p}=0.883$ & -12.80654 & 14.84117 \\
\hline DiastolicBPmm Hg & 77.1 & 78.4 & 11.4 & 11.6 & $\mathrm{p}=0.722$ & -5.86840 & 8.40087 \\
\hline $\begin{array}{l}\text { Glomerular filtration } \\
\mathrm{ml} / \mathrm{min}\end{array}$ & 36.3 & 29.1 & 12.7 & 16.9 & $\mathrm{p}=0.120$ & -0.29631 & 9.56903 \\
\hline
\end{tabular}

$\mathrm{DM}=$ Diabetes Mellitus, $\mathrm{BP}=$ blood pressure.

ESR obtained an OR = 1.959 (95\% CI; 1.193 - 3.217). Pearson chi-squared = 4.048; $\mathrm{p}<0.050$.

Besides information on sex by using non-parametric tests, it was obtained significant results with these others parameters:

1) Cholesterol: $\mathrm{p}=0.035$ (U of Mann Whitney).

2) Erythrocyte Sedimentation Rate: $p<0.001$ (U of Mann Whitney).

3) C-reactive protein: $p<0.001$ (Binomial test).

As for the CRP, the results were only as "positive” and "negative” in our laboratory. In patients with progression of the diabetic retinopathy were obtained: 13 negative cases (61.5\%) and 5 positive (38.4\%). In stabilized patients: 18 negative cases (83.3\%) and only 3 positive (16.6\%).

In group II, patients with progression of diabetic retinopathy, the ESR average precipitation was $49.47 \mathrm{~mm} / \mathrm{h}$ (standard deviation 11.73, $\mathrm{n}=19$ ) versus an average of $33.90 \mathrm{~mm} / \mathrm{h}$ from patients in group I or stabilized (standard deviation 11.92, $\mathrm{n}=20$ ). 


\section{Discussion}

In recent studies, the Dialysis Outcomes and Practice Patterns Study (DOPPS) conducted in different countries, have shown that life expectancy has improved in patients with end-stage nephropathy [21] [22].

This means, opposite what it was thought 10 years ago, nowadays the nephrologists have increased the average survival of patients with renal replacement therapy, but it is thought that with photocoagulation the retinopathy has no progression. This paradigm changed when we are meeting, in the daily practice in our medical unit, serious ocular problems as intraocular bleeding after photocoagulation.

This line of research started when we wondered: why some patients with diabetic retinopathy are stabilized with photocoagulation and others not? In our first research, we found the anemia as a factor related to the progression of diabetic retinopathy after photocoagulation [23], more than glycemia or others metabolic factors. This study enables us to investigate and to find that more than $90 \%$ of patients who underwent surgical caused by intraocular bleeding at our medical unit have diabetic kidney disease.

In this study, it is noticeable that patients with diabetic retinopathy treated with photocoagulation and an average hemoglobin value of $12.32 \mathrm{~g} / \mathrm{dl}$ had no intraocular bleeding, while those patients with an average hemoglobin value of $11.77 \mathrm{~g} / \mathrm{dl}$ had intraocular bleeding. The difference was not statistically significant.

As previously proved, "retinal hemorrhage, diabetic retinopathy, and macular degeneration are more common in Chronic Kidney Disease stages 3 to 5 than stages 1 to 2. Retinal hemorrhage was present in 39\% of patients with stages 3 to 5 (of that study). Most bleed were small, transient, and of no visual consequences [24].” But, our patients with kidney disease and intraocular bleeding have ended up in retinal surgery, When we compare metabolic variables of most patients who underwent intraocular surgery to treat intraocular bleeding against their peers (patients with diabetic nephropathy) only cholesterol appeared with a significant difference, but the relationship of cholesterol to both nephropathy and diabetic retinopathy complications is well established [2] [6].

Other studies have previously reported that C-reactive protein was statistically significant in their analysis [10] [17]. Other important finding was provided by Erythrocyte Sedimentation Rate (ESR). As previously mentioned, a limited number of inflammatory markers are associated with diabetes mellitus and kidney disease [10]. These markers, such as level of tumor necrosis factor or homocystein, are not routinely performed by any laboratory. Even with then on specificity of ESR, excessively high parameters can give us a more severe prognosis regarding both ocular and renal caused by diabetes mellitus.

There is limited literature about C-reactive protein and diabetes mellitus and it is hardly found published studies about the relationship between Diabetes Mellitus and ESR. In the only two published studies that were found, it is reported that both ESR and CRP are the two most common measurements of inflammation in clinical practice, in particular rheumatic disease and infections. ESR has been criticized as being neither sensitive nor specific. A variety of conditions as age, sex, anemia, and pregnancy may influence the CRP and ESR measurements. It is recognized that chronic kidney disease elevates the Erythrocyte Sedimentation Rate, probably by increasing the concentration of serum fibrinogen [25]. In another study, it was found that “... Age elevates ESR in healthy subjects. The reference range for ESR remains controversial, particularly in old people, whose normal values can be high as 40 to $50 \mathrm{~mm} / \mathrm{h}$...” and emphasizes in “... the conditions that interfere with ESR measurement are anemia, kidney failure, and anticoagulation with sodium heparin ...” another important detail is "regardless the influence of treatment with heparin, it is proved in vitro that sodium heparin mixed with blood of healthy donors elevates ESR from 6 to $14 \mathrm{~mm} / \mathrm{h}$ ” [26]. Nevertheless, even some of our patients use heparin, mainly those with stage 5; we have also patients with intraocular bleeding in stages 3 and 4 who do not use heparin.

\section{Comments}

We recognize that this study (We realized that sample size was small. We calculated this study with a case-control methodology, but yielded a sample size of 160 persons per group, this was excessive compared with the size of our medical unit and the characteristics of the patients that we needed. For this reason, we chose a cross sectional, comparative, analytical, and observational study to make the study feasible. And yes, we found that two of our patients with the ESR elevated have another pathology, both of them having a bacterial infection which would explain the difference. But the other patients in the non stabilized group did not have other pathologies that would explain an elevated erythrocyte sedimentation rate and an elevation of PCR, besides the age, anemia and chronic kidney disease, as it was mentioned in this report.) had a low population and our patients 
have almost all conditions by which inflammatory markers can be increased. However, it is remarkable the fact that the average Erythrocyte Sedimentation Rate value in patients of group I was less than $40 \mathrm{~mm} / \mathrm{h}$, whereas in group II was slightly less than $50 \mathrm{~mm} / \mathrm{h}$. These values, aforementioned, are related to healthy old people. Obviously, this does not apply to our population.

Statistical significance for both C-reactive protein and ESR shows us that if this work is confirmed by other studies, it would be advisable order these parameters in preoperative lab test in order to make a better prognosis of the surgery.

Similarly, it is suggested the recommendation to verify, prior to surgery, the renal function of patients to confirm the presence of Renal-Retinal Syndrome. This, may lead to better results and therefore improve the quality of life of patients.

\section{References}

[1] Brown, J.B., Pedula, K.L. and Summers, K.H. (2003) Diabetic Retinopathy: Contemporary Prevalence in a Well-Controlled Population. Diabetes Care, 26, 2637-2942. http://dx.doi.org/10.2337/diacare.26.9.2637

[2] Klein, R., Klein, B. and Moss, S. (1992) Epidemiology of Proliferative Diabetic Renitopathy. Diabetes Care, 15, 18751887. http://dx.doi.org/10.2337/diacare.15.12.1875

[3] Trevisan, R., Vedovato, M., Mazzon, C., Coracina, A., Iori, E., Tiengo, A., et al. (2002) Concomitance of Diabetic Retinopathy and Proteinuria Accelerates the Rate of Decline of Kidney Function in Type 2 Diabetic Patients. Diabetes Care, 25, 2026-2031. http://dx.doi.org/10.2337/diacare.25.11.2026

[4] Stolar, M. (2010) Glycemic Control and Compilations in type 2 Diabetes Mellitus. The American Journal of Medicine, 123, S3-S11. http://dx.doi.org/10.1016/j.amjmed.2009.12.004

[5] Williams, M.E. (2011) The Goal of Blood Pressure Control for Prevention of Early Diabetic Microvascular Complications. Current Diabetes Reports, 11, 323-329. http://dx.doi.org/10.1007/s11892-011-0193-z

[6] Del Cañizo-Gómez, F.J., Fernández Pérez, C., Moreno Ruiz, I., Pérez-Jáuregui, C.D., Silveira Rodríguez, B., González, L.T., et al. (2011) Microvascular Complications and Risk Factors in Patients with Type 2 Diabetes. Endocrinología y Nutrición, 58, 163-168. http://dx.doi.org/10.1016/j.endonu.2011.01.006

[7] Singh, D., Winocour, P. and Farrington, K. (2009) Erythropoietic Stress and Anemia in Diabetes Mellitus. Nature Reviews Endocrinology, 5, 204-210. http://dx.doi.org/10.1038/nrendo.2009.17

[8] Thomas, M., Tsalamandris, C., MacIsaac, R. and Jerums, G. (2005) Anaemia in Diabetes: An Emerging Complication of Microvascular Disease. Current Diabetes Reviews, 1, 107-126. http://dx.doi.org/10.2174/1573399052952587

[9] Conway, B., Miller, R., Klein, R. and Orchard, T. (2009) Prediction of Proliferative Diabetic Retinopathy with Hemoglobin Level. Archives of Ophthalmology, 127, 1494-1499. http://dx.doi.org/10.1001/archophthalmol.2009.274

[10] Kaul, K., Hodgkinson, A., Tarr, J.M., Kohner, E.M. and Chibber, R. (2010) Is Inflammation a Common Retinal-RenalNerve Pathogenic Link in Diabetes? Current Diabetes Reviews, 6, 294-303. http://dx.doi.org/10.2174/157339910793360851

[11] Klein, B.E., Knudtson, M.D., Tsai, M.Y. and Klein, R. (2009) The Relation of Markers of Inflammation and Endothelial Dysfunction to the Prevalence and Progression of Diabetic Retinopathy: Wisconsin Epidemiologic Study of Diabetic Retinopathy. JAMA Ophthalmology, 127, 1175-1182. http://dx.doi.org/10.1001/archophthalmol.2009.172

[12] Friedman, E.A. and L’Esperance, F.A. (1980) Diabetic Renal-Retinal Syndrome: The Prognosis Improves. JAMA Internal Medicine, 140, 1149-1150. http://dx.doi.org/10.1001/archinte.1980.00330200025011

[13] Cowan, C.L. (1987) Diabetic Renal-Retinal Syndrome: Does Tight Control Help? Transplantation Proceedings, 19, 86-89.

[14] Sessa, A., Battini, G., Meroni, M., Agneli, F., Giordano, F. and Tarelli, L.T. (1999) Renal-Retinal Diabetic Syndrome. Nephron, 83, 285-286. http://dx.doi.org/10.1159/000045529

[15] Izzedine, H., Fongoro, S., Pajot, O., Beaufils, H. and Deray, G. (2001) Retinopathy, Hematuria and Diabetic Nephropathy. Nephron, 88, 382-383. http://dx.doi.org/10.1159/000046025

[16] Meleth, A.D., Agrón, E., Chan, C.C., Reed, G.F., Arora, K., Byrnes, G., Csaky, K.G., Ferris III, F.L. and Chew, E.Y. (2005) Serum Inflammatory Markers in Diabetic Retinopathy. Investigative Ophthalmology \& Visual Science, 46, 4295-4301. http://dx.doi.org/10.1167/iovs.04-1057

[17] Shiraishi, F.G., StringuettaBelik, F., Oliveira e Silva, V.R., Martin, L.C., Hueb, J.C., De Souza Gonçalves, R., et al. (2012) Inflammation, Diabetes, and Chronic Kidney Disease: Role of Aerobic Capacity. Experimental Diabetes Research, 2012, Article ID: 750286. http://dx.doi.org/10.1155/2012/750286 
[18] Fante, R., Durairaj, V. and Oliver, S. (2010) Diabetic Retinopathy: An Update on Treatment. The American Journal of Medicine, 123, 213-216. http://dx.doi.org/10.1016/j.amjmed.2009.09.020

[19] Levey, A., Steven, L., Schmid, C., Zhang, Y., Castro, A., Feldman, H., et al. (2009) A New Equation to Estimate Glomerular Filtration Rate. Annals of Internal Medicine, 150, 604-612. http://dx.doi.org/10.7326/0003-4819-150-9-200905050-00006

[20] Varma, R., Macias, G.L., Torres, M., Klein, R., Peña, F.Y., Azen, S.P. and Los Angeles Latino Eye Study Group (2007) Biologic Risk Factors Associated with Diabetic Retinopathy: The Los Angeles Latino Eye Study. Ophthalmology, 114, 1332-1340. http://dx.doi.org/10.1016/j.ophtha.2006.10.023

[21] Mendelssohn, D., Yeates, K., Ethier, J., Trpeski, L., Na, Y., Bragg-Gresham, J., Eichleay, M.A., Pisoni, R.L. and Port, F.K. (2007) DOPPS Estimate of Patient Life Years Attributable to Modifiable Hemodialysis Practices in Canada. Nephrology News \& Issues, 21, 69-70, 72, 74-76 passim.

[22] Port, F.K., Pisoni, R.L., Bragg-Gresham, J.L., Satayathum, S.S., Young, E.W., Wolfe, R.A. and Held, P.J. (2004) DOPPS Estimates of Patient Life Years Attributable to Modifiable Hemodialysis Practices in the United States. Blood Purification, 22, 175-180. http://dx.doi.org/10.1159/000074938

[23] Sepúlveda, F.J., Pérez, P., Medinilla, M.G. and Aboytes, C.A. (2012) Anemia as a Factor Related to the Progression of Proliferative Diabetic Retinopathy after Photocoagulation. Journal of Diabetes and Its Complications, 26, 454-457. http://dx.doi.org/10.1016/j.jdiacomp.2012.04.013

[24] Deva, R., Alias, M.A., Colville, D., Tow, F.K.F., Ooi, Q.L., Chew, S., et al. (2011) Vision-Threatening Retinal Abnormalities in Chronic Kidney Disease Stages 3 to 5. Clinical Journal of the American Society of Nephrology, 6, 18661871. http://dx.doi.org/10.2215/CJN.10321110

[25] Costenbader, K., Chibnik, L. and Schur, P. (2007) Discordance between Erythrocyte Sedimentation Rate and C-Reactive Protein Measurements: Clinical Significance. Clinical and Experimental Rheumatology, 25, 746-749.

[26] Colomber, I., Pouchot, J., Kronz, V., Hanras, X., Capron, L., Duriex, P. and Wyplosz, B. (2010) Agreement between Erythrocyte Sedimentation Rate and C-Reactive Protein in Hospital Practice. American Journal of Medicine, 123, 863.e7-863.e13. 
Scientific Research Publishing (SCIRP) is one of the largest Open Access journal publishers. It is currently publishing more than 200 open access, online, peer-reviewed journals covering a wide range of academic disciplines. SCIRP serves the worldwide academic communities and contributes to the progress and application of science with its publication.

Other selected journals from SCIRP are listed as below. Submit your manuscript to us via either submit@scirp.org or Online Submission Portal.
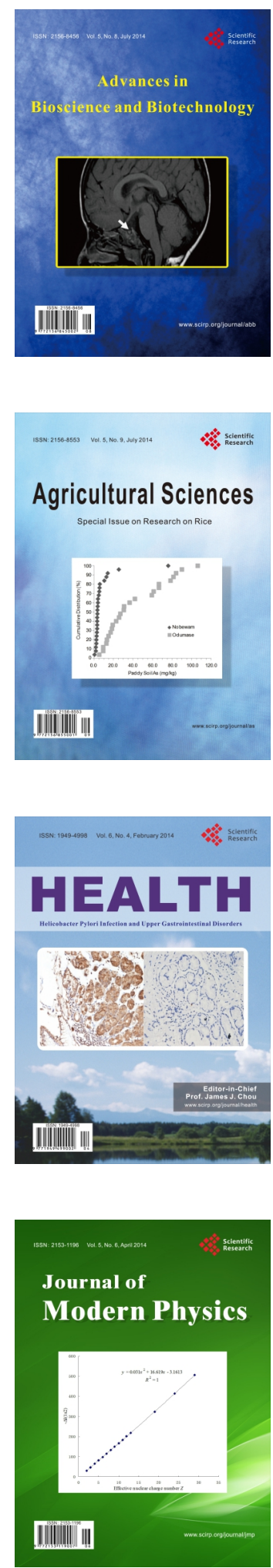
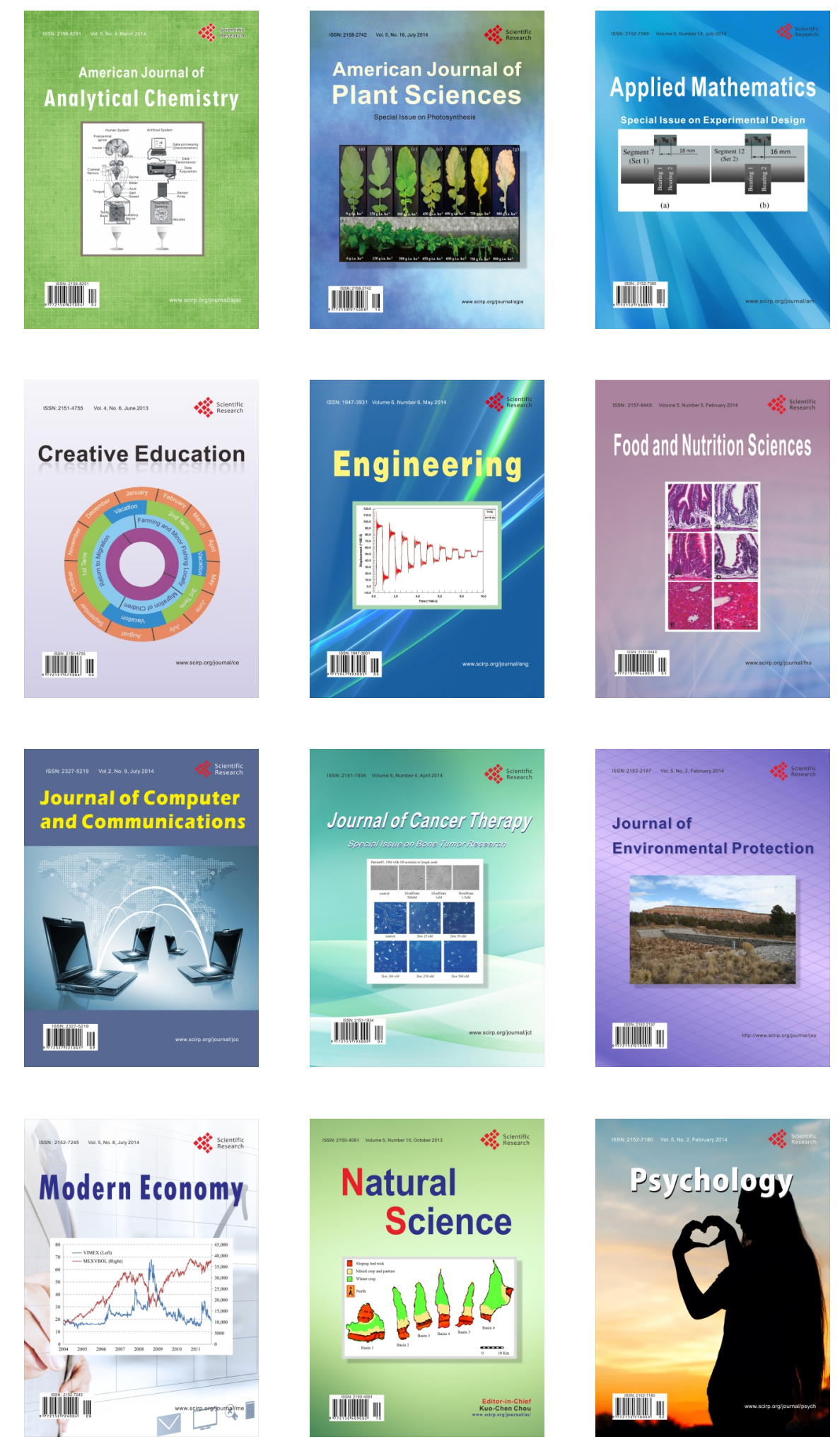